\title{
Fixed precision sequential sampling plans for leaf mines of Liriomyza sativae Blanchard (Diptera: Agromyzidae) in cucumber greenhouses
}

\section{Peyman Namvar $^{1}$; Mohammed Hassan Safaralizadeh ${ }^{2}$; Valiollah Baniameri $^{3}$ and Ali Asghar Pourmirza ${ }^{2}$}

1-Department of Plant protection, Jiroft and Kahnooj Recearch center for Agriculture.

2- Department of Entomology, Agriculture Faculty, Urmia University.

3-Department of Entomology, Iranian Research Institute of Plant Protection

ABSTRACT

This study was conducted to develop sequential sampling plans to estimate leaf mine density by Liriomyza sativae (Blanchard) at three fixed-precision levels in cucumber greenhouse. The within- greenhouse spatial patterns of leafmines were aggregated. The slopes and intercepts of Taylor's power law did not differ between years. A fixed-precision level sampling plan was developed using the parameters of Taylor's power law generated from total number of leafmines in a cucumber leaf at three precision levels $(D)$ of $0.1,0.25$ and 0.29 . The resulting sampling plans were tested with sequential bootstrap simulations $(n=500)$ using 10 independent data sets for validation. Bootstrap simulation within a wide range of densities demonstrated that actual $D^{\prime}$ values at desired $D=0.29$ averaged less than or equal to 0.29 in all cases. Even at the lowest density of leaf mine ( 0.27 mine per leaf), the actual mean $D^{\prime}$ was 0.28 at $D=0.29$. This result shows that the sampling plan developed in this study is effective and reliable for estimating the mine densities in cucumber greenhouses.

Keywords: Vegetable leaf miner, leaf mine, sequential sampling, spatial distribution, resampling simulation, greenhouse cucumber

\section{INTRODUCTION}

Leafminers belonging to the genus Liriomyza (Diptera: Agromyzidae) are regarded as pests in many crops due to their damage to leaves (Lopez et al. 2010). Liriomyza genus includes about 300 species distributed worldwide with 23 species being considered economically important (Parrella 1987, Kang et al. 2009). The leafminer fly, Liriomyza sativae Blanchard, originated from the Neotropics, was reportedly seen in Mexico and South America, but has rapidly disseminated to other countries in Europe, Africa and Asia (Lopez et al. 2010). In Iran, L. sativae was first seen in 2000. This species and L. trifolii Burgess have seriously damaged beans, peas, vegetables and tomatoes in the provinces of Khuzestan, Kerman and Tehran (Askary 1995, Kalantar hormozy et al. 2000, Javadzadeh 2004). At present, L. sativae mixed with $L$. trifolii which is mostly dominated by L. sativae in cucumber greenhouses throughout the country.

As a polyphagous insect, $L$. sativae affects many host plants including horticultural crops and all associated weeds (Lopez et al. 2010). Flowering plants which are readily infested and are known to facilitate the spread of the pest include chrysanthemum, gerbera, gypsophila and marigold, but there might be many other hosts, especially among compositae (Capinera 2005).

Leafminers have a relatively short life cycle, they are able to complete their development in 21-28 days under warm environments such as Florida. In tropical 
climates, numerous generations occur annually (Capinera 2001). Leibee (1984), determined growth at a constant $25^{\circ} \mathrm{C}$, and reported that about 19 days were required from egg deposition to emergence of the adult.

The management of agromyzid leafminers has been a topic of extensive research and scientific debate for the last three decades. Most of studies have focused on using synthetic and natural insecticides, which are commonly used similarly by both the small holder farmers and large-scale producers. However, their effectiveness has been doubted due to their broad-spectrum application, the impact on natural enemies and the development of resistance in target pests. Other control techniques, such as using yellow sticky traps or resistant host plants, currently have a very limited usage in some countries (Murphy and Lasalle 1999).

Spatial distribution is a behavioral response of the individuals of a species to habitat (Young and Young 1998, Southwood 1995). The information of spatial distribution (i.e., regular, random or aggregated) can determine what sampling program must be carried out, especially sequential sampling (Feng et al. 1993, Elliot and Kiechhefer 1986).

A successful management of leafminers strongly depends on the development of an appropriate sampling plan (i.e., easy to implemented suitable for rapid decisionmaking processes). In sampling programs, precision and cost-effectiveness are two most important factors that need to be considered (Pedigo 1994). For example, compared with fixed-sample size sampling, a fixed-precision sequential sampling can result in a 35-50\% reduction in sampling effort (Binns 1994). The development of a sequential sampling scheme with a fixed statistical precision, therefore, may be useful for estimating leaf mine density by $L$. sativae in cucumber greenhouses, which in turn, would be valuable for ecological and pest management studies.

The objectives of the present study were to determine the spatial distribution patterns for leafmines developed by L. sativae larvae, and to develop and evaluate a fixed-precision sequential sampling for estimating leaf mine densities in cucumber greenhouses.

\section{MATERIAL AND METHODS}

\section{The study site}

Field experiments were carried out at an experimental greenhouse located in Jiroft (Kerman, Iran) during growing seasons (November- April) in 2007-2009. The cucumber Cucumis sativus cv. RS189 I SINA F1 (Royal Sluis, Netherlands) was grown under greenhouse on eight 45-m-long rows. Cultivations, fertilization and irrigations were conducted according to the conventional agronomic practices. No other pesticides were applied.

\section{Sampling program}

One single leaf of a cucumber plant was selected as a sample unit. Then, it was inspected in situ to record the total number of leafmines of $L$. sativae per leaf. 40 Cucumber leaves were randomly sampled and counted for mine density of $L$. sativae once a week during morning.

\section{Sampling plan development} following:

Dispersion indices of leafmines were calculated using Taylor's power law as

$$
S^{2}=a m^{b} \text { or } \log S^{2}=\log a+b \log m
$$

Where the parameters $a$ and $b$ are a scaling factor related to sample size and an index of aggregation, respectively (Southwood and Henderson, 2000). 
The values of $F$ and $P$ acquired from regression equations were used to test whether the Taylor's coefficient $(b)$ was significantly different from 0 . In addition, to test for their difference from 1 , the statistic $t$ (as $t=($ slope -1$\left.) / S E_{\text {slope }}\right)$ was used. Here, slope and $S E_{\text {slope }}$ are Taylor's coefficients and their standard deviations in regression equations, respectively.

Since Taylor's coefficients were estimated by two-year data, the difference of distribution coefficients between years, were tested by the statistic $t$ $\left(t=\frac{b_{1}-b_{2}}{\sqrt{S E_{1}^{2}+S E_{2}^{2}}}\right)$ (Feng and Nowierski 1992a, b). Here, $b_{1}$ (and $S E_{1}$ ) and $b_{2}$ (and $S E_{2}$ ) are the Taylor's coefficients (and their standard errors) for the first and the second year, respectively.

The data of two years were integrated and a total distribution coefficient was estimated only when the difference between coefficients of two years was not significant.

Coefficients from the Taylor's power law regression were used to develop fixedprecision sequential sampling plan. The sampling stop line was calculated by following formula (Green 1970):

$$
\log T_{n}=\frac{\log \left(D^{2} / a\right)}{b-2}+\frac{b-1}{b-2} \log n
$$

Where $T_{n}$ is the cumulative number of leafmines over $n$ samples, $D$ is the fixed level of precision, and $a$ and $b$ are from the Taylor's regression. Precision levels were set between 0.1 and 0.29 because estimates of population density within $10 \%$ and $25 \%$ of the mean are considered adequate for ecological studies and pest management decisions respectively (Southwood and Henderson 2000).

Validation of sampling plans

Actual precision levels obtained from the sequential sampling program at specified levels of precision were evaluated by bootstrap simulation (Efron and Tibshirani 1986). The simulations were performed on independently collected data sets not used in developing the sampling plan. For this purpose, ten independent data sets were collected in 2009. The mean densities of these data sets ranged from 0.27 to 31.83 mines per leaf. The sample size of each data set consisted of 40 leaves.

Resampling for Validation of Sampling Plans (RVSP) software developed by Naranjo and Hutchison (1997) was used for bootstrap simulations. The RVSP was used to resample each of ten data sets with a replacement option until the stop line had been reached. In addition to the initial fixed- precision levels of $0.1,0.25$ and 0.29 , a minimum sample size of 3 was used for all simulations. Resampling was repeated 500 times for each data set, producing the average precision level and the average, minimum and maximum sample size.

\section{RESULTS AND DISCUSSION}

\section{Spatial distribution}

Mean numbers of leaf mines per leaf ranged from 0.26 to 12.48 in 2008 and from 0.07 to 37.4 in 2009. Taylor's equations for the growing seasons were obtained as $\log S^{2}=0.249+1.181 \log m\left(F_{26}=277.405, \quad P<0.05 ; \quad\right.$ Table 1$)$ and $\log S^{2}=0.259+1.219 \log m\left(F_{23}=1641.347, P<0.05\right)$, both with a great degree of fit $(>$ $0.90)$. In addition, the coefficient $b$ was significantly greater than 1 (2007-2008: $t_{26}=2.55$, $P<0.05$; 2008-2009: $t_{23}=7.3, P<0.05$; Table 1 ), implying an aggregated distribution. 
Table 1: Spatial distribution of Liriomyza sativae on cucumber using Taylor's power law regression analysis.

\begin{tabular}{ccccccc}
\hline Growing season & $\mathrm{b} \pm \mathrm{SE}$ & Loga $\pm \mathrm{SE}$ & $\mathrm{R}^{2}$ & $\mathrm{~F}$ & $\mathrm{t}$ & $\mathrm{Df}$ \\
\hline $2007-2008$ & $1.181 \pm 0.071$ & $0.249 \pm 0.034$ & 0.917 & $277.405^{* *}$ & $2.55^{*}$ & 26 \\
2008-2009 & $1.219 \pm 0.03$ & $0.259 \pm 0.028$ & 0.985 & $1641.347^{* *}$ & $7.3^{*}$ & 23 \\
Overall & $1.217 \pm 0.036$ & $0.251 \pm 0.022$ & 0.97 & $1629.611^{* *}$ & $7.23^{*}$ & 50 \\
\hline
\end{tabular}

*and** show significant difference at 0.05 level with 0 and 1 , respectively

The comparison of annual distribution coefficients using $t$-statistic showed no significant difference $\left(\mathrm{t}_{\text {slope }}=0.31\right.$ and $\left.\mathrm{t}_{\text {intercept }}=0.75, \mathrm{P}<0.05\right)$. Therefore, the annual data was pooled between years, and overall distribution coefficients were calculated (Tables 1).

Previous studies have been stated an aggregated form for the spatial distribution pattern of Liriomyza spp. (Zenjun 1997; Yan 1998; Hammad and Nemer 2000; Lee et al. 2005). Here, the estimated Taylor index $b$ was between 1.181 and 1.219. In other studies, the estimated values of this index has been ranged from 1.12 to 1.62, for example 1.12 on lettuce (Burgio et al., 2005), 1.15 and 1.19 for L. trifolii mines and larvae on chrysanthemum (Jones and Parrella 1986),1.16 for L. sativae on beans (Hanna et al. 1987), 1.19 for L. huidobrensis larvae on celery (Heinz and Chaney 1995), 1.51 for L. trifolii larvae on celery (Beck et al. 1981), and 1.62 for L. trifolii mines on greenhouse tomatoes (Lee et al. 2005).

To explain these differences, some researchers believe that the spatial distribution of Liriomyza sp on tomato leaves is more aggregated than on other host plants (Lee et al., 2005). But considering the results of similar studies in various parts of the world, it might be concluded that the differences are at least partly caused by the different host plants, pest population density and environmental conditions such as weather, greenhouse ventilation and pesticide applications (Zenjun 1997, Yan 1998, Burgio et al. 2005).

\section{Sequential sampling}

Fixed- precision sequential sampling stop lines were calculated using equation 1 at three levels of precision (Fig. 1).

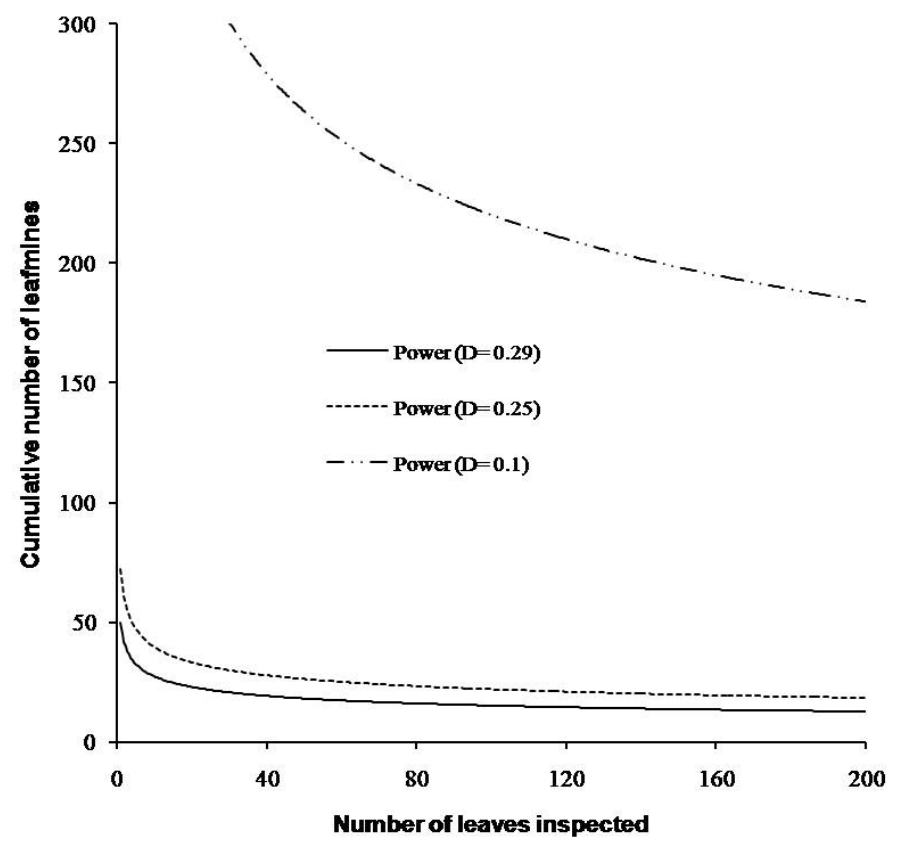

Fig. 1: Sequential sampling stop lines for fixed- precision level (D) of 0.1, 0.25 and 0.29 for various Liriomyza sativae leaf mine densities.

Utilization of this sampling method requires that sampling units must be taken sequentially until the cumulative number of mines exceeds stop line values for the 
number of sample units collected. The mean density can then be estimated as the quotient of the cumulative number of leafmines divided by the number of sample units. The leaf mines stop lines showed that the required sample size increased with the precision level increased. For example, only 9 sample units needed to be inspected to achieve $\mathrm{D}=0.29$ when mean density was 3.42 leafmines per sample unit. However sample size increased dramatically to 71 to achieve precision level of $D=0.1$ (Table 2).

Table 2: Statistics for a 500 simulation runs for a fixed- precision sequential sampling plan with desired precision levels (D) of $0.1,0.25$ and 0.29 on ten independent data sets collected in 2009 .

\begin{tabular}{|c|c|c|c|c|c|c|}
\hline \multirow{2}{*}{\multicolumn{2}{|c|}{ Data set $^{\mathrm{a}}$}} & \multicolumn{5}{|c|}{ Statistics for 500 simulation runs } \\
\hline & & \multicolumn{5}{|c|}{ Sample size } \\
\hline Series & $\mathrm{m} \pm \mathrm{SE}$ & $\mathrm{m}^{\prime}$ & mean & $\max$ & $\min$ & Average $D^{\prime}$ \\
\hline \multicolumn{7}{|c|}{ Desired $D=0.1$} \\
\hline 1 & $0.27 \pm 0.11$ & 0.28 & 516 & 650 & 200 & 0.10 \\
\hline 2 & $0.54 \pm 0.16$ & 0.52 & 316 & 383 & 200 & 0.09 \\
\hline 3 & $0.76 \pm 0.17$ & 0.75 & 237 & 281 & 196 & 0.08 \\
\hline 4 & $1.33 \pm 0.28$ & 1.34 & 151 & 187 & 117 & 0.10 \\
\hline 5 & $1.74 \pm 0.42$ & 1.73 & 123 & 166 & 89 & 0.10 \\
\hline 6 & $2.27 \pm 0.36$ & 2.32 & 97 & 118 & 81 & 0.09 \\
\hline 7 & $3.42 \pm 0.41$ & 3.48 & 71 & 85 & 61 & 0.10 \\
\hline 8 & $6.5 \pm 1.04$ & 6.69 & 42 & 54 & 31 & 0.09 \\
\hline 9 & $10.93 \pm 1.43$ & 11.4 & 28 & 37 & 23 & 0.09 \\
\hline 10 & $31.83 \pm 3.85$ & 31.76 & 13 & 17 & 10 & 0.11 \\
\hline Average & $5.86 \pm 2.96$ & 6.03 & 159.4 & 197.8 & 100.8 & 0.095 \\
\hline \multicolumn{7}{|c|}{ Desired $D=0.25$} \\
\hline 1 & $0.27 \pm 0.11$ & 0.29 & 85 & 143 & 46 & 0.24 \\
\hline 2 & $0.54 \pm 0.16$ & 0.54 & 52 & 80 & 29 & 0.22 \\
\hline 3 & $0.76 \pm 0.17$ & 0.77 & 39 & 68 & 24 & 0.20 \\
\hline 4 & $1.33 \pm 0.28$ & 1.4 & 25 & 46 & 13 & 0.24 \\
\hline 5 & $1.74 \pm 0.42$ & 1.82 & 20 & 33 & 10 & 0.26 \\
\hline 6 & $2.27 \pm 0.36$ & 2.43 & 16 & 25 & 10 & 0.21 \\
\hline 7 & $3.42 \pm 0.41$ & 3.54 & 12 & 17 & 8 & 0.20 \\
\hline 8 & $6.5 \pm 1.04$ & 6.94 & 7 & 13 & 4 & 0.24 \\
\hline 9 & $10.93 \pm 1.43$ & 11.63 & 5 & 8 & 3 & 0.19 \\
\hline 10 & $31.83 \pm 3.85$ & 31.74 & 3 & 4 & 3 & 0.21 \\
\hline Average & $5.86 \pm 2.96$ & 6.11 & 26.4 & 43.7 & 26.4 & 0.221 \\
\hline \multicolumn{7}{|c|}{ Desired $D=0.29$} \\
\hline 1 & $0.27 \pm 0.11$ & 0.3 & 63 & 104 & 28 & 0.28 \\
\hline 2 & $0.54 \pm 0.16$ & 0.55 & 38 & 62 & 23 & 0.26 \\
\hline 3 & $0.76 \pm 0.17$ & 0.78 & 29 & 47 & 16 & 0.24 \\
\hline 4 & $1.33 \pm 0.28$ & 1.45 & 19 & 39 & 9 & 0.28 \\
\hline 5 & $1.74 \pm 0.42$ & 1.88 & 15 & 28 & 8 & 0.28 \\
\hline 6 & $2.27 \pm 0.36$ & 2.43 & 12 & 22 & 7 & 0.24 \\
\hline 7 & $3.42 \pm 0.41$ & 3.52 & 9 & 15 & 6 & 0.21 \\
\hline 8 & $6.5 \pm 1.04$ & 7.02 & 6 & 12 & 3 & 0.29 \\
\hline 9 & $10.93 \pm 1.43$ & 11.84 & 4 & 7 & 3 & 0.21 \\
\hline 10 & $31.83 \pm 3.85$ & 31.28 & 3 & 3 & 3 & 0.20 \\
\hline Average & $5.86 \pm 2.96$ & 6.1 & 19.8 & 33.9 & 10.6 & 0.249 \\
\hline
\end{tabular}

${ }^{\mathrm{a}}$ Each data set contained 40 observations.

Several sampling programs have been developed for different Liriomyza species on greenhouse and field vegetable crops. Musgrave et al. (1975) found that yellow sticky traps could be used for rapid detection of adult $L$. trifolii population fluctuation and Parrella and Jones (1985) suggested sequential sampling plans using yellow sticky traps with two large and small sizes for trapping mature insects of $L$. trifolii in chrysanthemum greenhouse. They proposed that with a precision of 0.25 only $18 \%$ of 
the traps were needed to be counted. Jonson et al. (1980) suggested that the pupal tray survey was a fast and accurate method of estimating pupal density. Although monitoring of leafminer adult or pupal stages may be accomplished with relatively simple tools, these methods produce either large estimation errors or contain inherent time delays by predicting subsequent rather than present leafminer densities (Trumble and Nakakihara 1983, Parrella et al. 1989). Moreover, the relationship between adults trapped and larval densities in plants is difficult to elucidate, particularly in commercial greenhouses where applications of pesticides cause adult and larval populations to fluctuate dramatically (Parrella and Jones 1985). In another study using Taylor index coefficients, Heinz and Chaney (1995) designed a sequential sampling plan for L. huidobrensis larvae on celery, which was very precise in estimating decision-making lines regarding the aggregated frequency of larvae and larval channels.

Counting mines has two advantages over yellow sticky trap sampling and pupal tray survey. Firstly, the leafmine sampling allows assessing the damage easily because the major source of the damage by Liriomyza species is the accumulation of leafmines during the growing seasons (Chandler and Gilstrap 1987). The other is that result of the leafmine sampling data can be directly incorporated into a control decisionmaking program. Therefore, the leafmine sampling program is needed to improve timing of control measures, and to facilitate the establishment of economic threshold values (Lee et al. 2005).

\section{Validation of sampling plans}

Variability in precision level, density estimation and sample size from simulation sampling were used as criteria for evaluating performance of the Fixedprecision sequential sampling plan according to Hutchison et al. (1988). A sampling plan is considered reliable only if $>90 \%$ of the observed $D^{\prime}$ values are less than the desired $D$ (Hutchison 1994). In 9 out of 10 data sets, the observed $D^{\prime}$ values were less than or equal to the desired $D$ values, indicating that the plan was reliable (Table 2).The estimated means $\left(m^{\prime}\right)$ also did not differ significantly with the actual means $(m)$ for all data sets on which simulation were performed and at all levels of precisions. The simulation runs also provided the information on variability in the required sample size (Table 2). The required sample size was more variable for low densities $(\mathrm{m}<2)$ than for intermediate $(2<\mathrm{m}<6.5)$ and high densities $(\mathrm{m}>6.5)$.

In pest management programs, reduced cost may be worth a loss in precision as long as precision is sufficient to make correct decisions. The simulation results indicated that the relaxed desired precision level of $D=0.29$ was acceptable and practicable because the averaged observed $D^{\prime}=0.249$ was sufficient for pest management purpose (Table 2). The similar results have been observed for L trifolii by Lee et al. (2005) recommending that the precision of 0.3 would be sufficient in sampling programs, and other arthropods, and these results illustrate the need for validation process (O'Rourke and Hutchison 2003). Thus based on the simulation results, the sampling plan with $D=0.29$ is recommended for $L$. sativae management applications.

In conclusion, our study indicated that the spatial distribution of L. sativae mines in cucumber greenhouses was of aggregated form and the fixed precision sampling scheme developed using Green's method was acceptable for estimating leaf mine densities in commercial cucumber greenhouses. Therefore, the sampling strategies provided here can be used to obtain a rapid estimate of leaf mine densities with minimal effort. In addition, the knowledge of density level of leafmines would provide the solid basis for optimal decision- making in IPM programs for L. sativae. 


\section{ACKNOWLEDGMENT}

We are grateful for the technical assistance of Mohiseny AA, Amiri R, Niknafs R, Roshan K and Bedrood A, for their helps.

\section{REFERENCES}

Askari, M. (1995). Some biological aspects of Liriomyza trifolii. In: Abstract of 12th Iranian Plant Protection Congress, Karaj, 2-7 Sep 1995

Beck, HW.; Musgrave, CA.; Strandberg, JO. and Genung, WG. (1981). Spatial dispersion patterns of Liriomyza sp on celery. In: Schuster DJ (ed) Proceedings of 2nd IFAS-Industry Conference Biology and Control of Liriomyza leafminers. Institute Food Agricultural Science, University of Florida, Gainesville, 1981

Binns, MR. (1994). Sequential sampling for classifying pest status. In: Pedigo LP, Buntin GD (ed) Handbook of sampling methods for arthropods in agriculture. CRC, Boca Raton, FL, pp. 137- 174.

Burgio, G.; Lanzoni, A.; Masetti, A. and Manucci, F. (2005). Spatial Patterns and Sampling Plan for Liriomyza huidobrensis (Diptera: Agromyzidae) and Related Parasitoids on Lettuce. Environ. Entomol 34: 178-183.

Capinera, JL. (2001). Handbook of vegetable pests. Academic Press, Newyork

Capinera, JL. (2005). Vegetable leaf miner: Liriomyza sativae Blanchard (Diptera: Agromyzidae). http://www.creatures. Ifas.Ufl.Edu. Cited 25 Jan 2005

Chandler, LD. and Gilstrap, FE. (1987). Seasonal fluctuation and age structure of Liriomyza trifolii larval population on bell peppers. J Econ Entomol 80:102- 106

Croft, BA.; Welch, SM. and Dover, MJ. (1976). Dispersion statistics and sample size estimates for populations of the mite's species Panonychus ulmi and Amblyseius fallacies on apple. Environ Entomol 5: 227-233

Efron, B. and Tibshirani, R. (1986). Bootstrap methods for standard errors, confidence intervals and other measures of statistical accuracy. Stat Sci 1: 54- 77

Elliott, NC. and Kieckhefer, RW. (1986). Spatial distributions of cereal aphids in winter wheat and spring oats in South Dakota. Environ Entomol 16: 896-901

Feng, MG. and Nowierski, RM. (1992a). Spatial distribution and sampling plans for four species of cereal aphids (Homoptera: Aphididae) infesting spring wheat in southwestern Idaho. J Econ Entomol 85: 830-837

Feng, MG. and Nowierski, RM. (1992b). Variation in spatial patterns of the Russian wheat aphid (Homoptera: Aphididae) among small grain in northwestern United States. Environ Entomol 21: 1029-1034

Feng, MG.; Nowierski, RM.; Zeng, Z. and Scharen, AL. (1993). Estimation of population density of the Russian wheat aphid (Homoptera: Aphididae) from the proportion of grain tillers with the different tally threshold of aphids. J. Econ Entomol 86: 427-435

Green, RH (1970). On fixed precision level sequential sampling. Res Popul Ecol 12: 249-251

Hammad, EMA. Nemer, NM. (2000). Population densities, spatial pattern and development of the pea leafminer (Diptera: Agromyzidae) on cucumber, swisschard and bean. J Agri Sci 134: 61-68

Hanna, HY.; Story, RN. and Adams, AJ. (1987). Influence of cultivar, nitrogen and frequency of insecticide application on vegetable leafminer population density and dispersion on snap bean. J Econ Entomol 80: 107-110 
Heinze, KM. and Chaney, WE. (1995). Sampling for Liriomyza huidobrensis (Diptera: Agomyzidae) Larvae and damage in celery. Environ Entomol 24: 204211

Hutchison, WD. (1994). Sequential sampling to determine population density. In: Pedigo LP, Buntin GD (ed) Handbook of sampling methods for arthropods in agriculture. CRC, Boca Raton FL, pp. 207- 243.

Hutchison, WD.; Hogg, DB.; Poswal, MA.; Berberet, RC. and Cuperus, GW. (1988). Implications of the stochastic nature of Kuno's and Green's fixed- precision stoplines: sampling plans for the pea aphid (Homoptera: Aphididae) in alfalfa as an example. J Econ Entomol 81: 749-758

Javadzadeh, M. (2004). Study on efficacy of some insecticides against Liriomyza trifolii (Burgess) on autumn cucumber in Varamin. In: Abstract of 16th Iranian Plant Protection Congress, University of Tabriz, Tabriz, 28 Aug - 1 Sep 2004

Johnson, M W.; Oatman, ER.; Wyman, JA. and Van, Steenweek RA. (1980). A technique for monitoring Liriomyza sativae in fresh market tomatoes. J Econ Entomol 73: 552-555

Jones, VP. and Parrella, MP. (1986). Development of sampling strategies for larvae of Liriomyza trifolii (Dip: Agromyzidae) in chrysanthemums. Environ Entomol 15: 268-273

Kalantar Hormozy, F.; Sahragard, Al.; Mohageri, R. and Jalali Sandi J. (2000). Introduction of vegetable leaf miner Liriomyza sativae Blanchard in Khuzestan Province In: Abstract of $14^{\text {th }}$ Iranian Plant Protection Congress, Isfahan University of Technology, 5-8 Sep 2000

Kang, L.; Cheng, B.; Wei, JN. and Xian, LT. (2009). Roles of thermal adaptation and chemical ecology in Liriomyza distribution and control. Ann Rev Entomol 54:127-45

Lee, DH.; Park, JJ.; Park, H. and Cho, K. (2005). Estimation of leafmine density of Liriomyza trifolii in cherry tomato greenhouse using fixed precision sequential sampling plans. J Asia-Pacific Entomol 8: 81-86

Leibee, GL. (1984). Influence of temperature on development and fecundity of Liriomyza trifolii (Burgess) (Diptera: Agromyzidae) on celery. Environ Entomol 13: 497-501

López, R.; Carmona, D.; Vincini, MA.; Monterubbianesi ,G. and Caldiz, D, (2010). Population dynamics and damage caused by the leafminer Liriomyza huidobrensis Blanchard (Diptera: Agromyzidae), on seven potato processing varieties grown in temperate environment. Neotrop Entomol 39: 108-114

Malhado, ACM. and Petrere, JM. (2004). Behavior of dispersion of indices in pattern detection of a population of Angico, Anandnanthera peregrine (Legominose). Brazil J Biol 64: 243- 249

Murphy, ST. and Lasalle, J. (1999). Balancing biological control strategies in the IPM of new world invasive Liriomyza leafminers in field vegetable crops. Biocontrol News and Information, 20: 91-104

Musgrave, C.; Poe, S. and Bennett, D, (1975). Leafminer population estimation in poly cultured vegetables. Proceedings of Fla State Hortic Soc 88: 156-160

Nestel, D.; Cohen, H.; Saphir, N.; Klein, M. and Mendel, Z. (1995). Spatial distribution of scale insect: comparative study using Taylor's power law. Environ Entomol 24: 506-512

Naranjo, SE. and Hatchison, WD. (1997). Validation of arthropod sampling plans using a Resampling approach: Software and analysis. Am Entomol 43: 48-47.

O'Rourke, PK. and Hutchison, WD. (2003). Sequential sampling plans for estimating 
European corn borer (Lepidoptera: Crambidae) and corn earworm (Lepidoptera: Noctuidae) larval density in sweet corn ears. Crop protect. 22: 903- 909

Parrella, MP. (1987). Biology of Liriomyza. Ann Rev Entomol 32: 201-224

Parrella, MP. and Jones, VP. (1985). Yellow Traps as Monitoring Tools for Liriomyza trifolii (Diptera: Agromyzidae) in Chrysanthemum Greenhouses. J Econ Entomol 78: 53-56

Parrella, MP.; Jones, VP.; Malais, MS. and Hienz, KM. (1989). Advances in sampling in ornamentals. Fla Entomol 42: 394- 402

Pedigo, LP. (1994). Introduction to sampling arthropod populations. In: Pedigo LP, Buntin GD (ed) Handbook of sampling methods for arthropods in agriculture. CRC, Boca Raton FL, pp. 1-11.

Pedigo LP. and Buntin GD. (1994). Handbook of sampling methods for arthropods in agriculture. CRC Boca Raton Florida.

Southwood TRE (1995). Ecological methods, with particular reference to the study of insect population. Chapman and Hall, London

Southwood TRE, Henderson PA (2000). Ecological methods. 3rd edition. Blackwell Sciences, Oxford

Taylor LR (1984). Assessing and interpreting the spatial distributions of insect populations. Ann Rev Entomol 29: 321- 357

Trumble JT, Nakakihara H (1983). Occurrence paratization and sampling of Liriomyza species infesting celery in California. Environ Entomol 12: 810- 814

Yan C (1998). Spatial pattern and vertical distribution of vegetable leafminer Liriomyza sativae Blanchard (Diptera: Agromyzidae). J Fuj Agri fore uni. DOI: CNKI:SUN:FJND.0.1998-03-013

Young LJ, Young LH (1998). Statistical ecology. Kluwer Academic Pub Boston

Zenjun S (1997). Spatial distribution pattern and sampling methods on Liriomyza sativae. J Fuj Agri fore uni. DOI: cnki:ISSN:1001-3601.0.1997-05-007. 